\title{
Topographic Organization of Neurons in the Acoustic Thalamus That Project to the Amygdala
}

\author{
Joseph E. LeDoux, ${ }^{1}$ Claudia Farb, ${ }^{1}$ and David A. Ruggiero ${ }^{2}$ \\ ${ }^{1}$ Center for Neural Science, New York University, New York, New York 10003, and 'Laboratory of Neurobiology, \\ Department of Neurology, Cornell University Medical College, New York, New York 10021
}

\begin{abstract}
Projections from the posterior thalamus to the amygdala have been implicated in the processing of the emotional significance of acoustic stimuli. The aim of the present studies was to determine which areas of the amygdala receive afferents from posterior thalamic structures that, in turn, receive afferents (presumably acoustic afferents) from the inferior colliculus. Projections from the posterior thalamus to the amygdala and striatum were examined in rats using anterograde and retrograde axonal transport techniques. Following injections of WGA-HRP into the posterior thalamic areas [including the medial division of the medial geniculate body, the posterior intralaminar nucleus (PIN) and the medial posterior complex (POM)], anterograde transport was seen in the lateral (AL), central (ACE), medial (AM), and basomedial (ABM) nuclei of the amygdala and in the amygdalostriatal transition area (AST) and posterior caudate putamen (CPU). Injection of WGA-HRP into each anterogradely labeled area produced retrograde transport to the posterior thalamus, but the pattern of transport varied with the site of the injection. Injections in AL and AST produced retrograde transport to neurons in the medial division of the medial geniculate body (MGM), PIN, suprageniculate nucleus (SG) and, to a lesser extent, the lateral posterior nucleus (LP). Injections of the $A C E, A M$, and $A B M$, in contrast, only labeled cells in POM. While the MGM, PIN, and SG each receive afferents from the inferior colliculus, POM does not. AL and AST, therefore, receive inputs from thalamic areas that, in turn, receive inputs from the inferior colliculus.
\end{abstract}

Projections from the posterior thalamus to the amygdala have been implicated in the processing of the emotional significance of acoustic stimuli (LeDoux et al., 1984, 1985, 1986a, b; Iwata et al., 1986). The exact areas of the posterior thalamus and amygdala involved are not known. Since these direct thalamo-amygdala projections are believed to transmit acoustic information, the critical area or areas of the amygdala should receive afferents from regions of the thalamus that, in turn, receive afferents from brain-stem auditory nuclei, particularly from the inferior colliculus.

\footnotetext{
Received June 9, 1989; revised Aug. 24, 1989; accepted Sept. 19, 1989.

Supported by MH38774 and a Grant in Aid from the New York Heart Association. J.E.L. is an Established Investigator of the American Heart Association The studies described in this paper were performed in the Laboratory of Neurobiology at Cornell University Medical College.

Correspondence should be addressed to Dr. J. E. LeDoux, Center for Neural Science, Meyer Building, New York University, 6 Washington Place, New York, NY 10003.

Copyright (C) 1990 Society for Neuroscience $0270-6474 / 90 / 041043-12 \$ 02.00 / 0$
}

In recent studics we have characterized the terminal fields of afferents in the posterior thalamus from the inferior colliculus in the rat (LeDoux et al., 1985, 1987a). These observations defined the rodent acoustic thalamus anatomically and allowed us to determine, in the experiments reported here, exactly which regions of the amygdala receive afferents from thalamic acoustic processing areas. To accomplish this, we identified the location of anterogradely transported WGA-HRP in amygdaloid nuclei following injections in the posterior thalamus. We then determined the cytoarchitectural location of thalamic cells retrogradely labeled following injections of WGA-HRP or FluoroGold (FG) in individual amygdaloid nuclei. In addition, we examined whether thalamic cells retrogradely labeled with FG following amygdaloid injections are located within areas containing anterograde transport following injection of WGA-HRP into the inferior colliculus.

\section{Materials and Methods}

Male Sprague-Dawley rats weighing 300-350 gm were anesthetized with Forane (3\% in $100 \%$ oxygen) or chloral hydrate $(420 \mathrm{mg} / \mathrm{kg}$, i.p.) and placed in a stereotaxic frame. Wheat germ agglutinin-conjugated horseradish peroxidase (WGA-HRP) or FG was ejected iontophoretically into regions of the midbrain, thalamus, or amygdala, as described below. In double-labeling studies, involving transport of WGA-HRP and FG, WGA-HRP was injected in a second surgical procedure conducted 2 or $3 \mathrm{~d}$ after the $\mathrm{FG}$ injection.

WGA-HRP was dissolved in Tris $\mathrm{HCl}(\mathrm{pH} \mathrm{8.6)} \mathrm{to} \mathrm{a} \mathrm{concentration} \mathrm{of}$ $5 \%$ and loaded into glass capillary tubing with tips pulled and broken back to diameters of $30-40 \mu \mathrm{m}$. FG was dissolved in $0.2 \mathrm{M}$ acetate buffer (pH 3.3) to a concentration of $1-2 \%$ and loaded in pipettes with $20-30$ $\mu \mathrm{m}$ tips. Positive direct current (WGA-HRP, $4.5 \mu \mathrm{A} ; \mathrm{FG}, 1.5 \mu \mathrm{A}$ ) delivered in pulses ( $7 \mathrm{sec}$ on, $7 \mathrm{sec}$ off) was passed through the pipette for 10-20 min using a Midgard iontophoresis unit. Following completion of the injection, the pipette was removed and the wound closed. After recovering from the anesthesia under a heat lamp, the animal was returned in its home cage to the housing area.

The animals were killed by pentobarbital $(120 \mathrm{mg} / \mathrm{kg}$, i.p.) overdose after appropriate survival times (WGA-HRP, $48 \mathrm{hr}$; FG, 5-7 d) and perfused through the left ventricle of the heart with normal saline followed by appropriate fixative solutions for WGA-HRP (Mesulam, 1978) and FG (Schmued and Fallon, 1986). In studies involving both WGAHRP and FG, a combination of WGA-HRP and FG fixatives was used (Schmued and Fallon, 1986). Once fixed, the brains were removed, frozen, and sectioned. In WGA-HRP experiments, the sections were processed histochemically using the tetramethylbenzidine (TMB) reaction (Mesulam, 1978). The sections were then mounted on gelatincoated slides, dehydrated, and coverslipped with Histoclad. FG sections were mounted on slides, dehydrated, and coverslipped with DPX. Labeled cells and terminal-like processes were visualized with the aid of a microscope fitted with a dark-field condenser and fluorescence optics. Sclccted sections from representative cases were drawn using a camera lucida attached to the microscope or were photographed. 


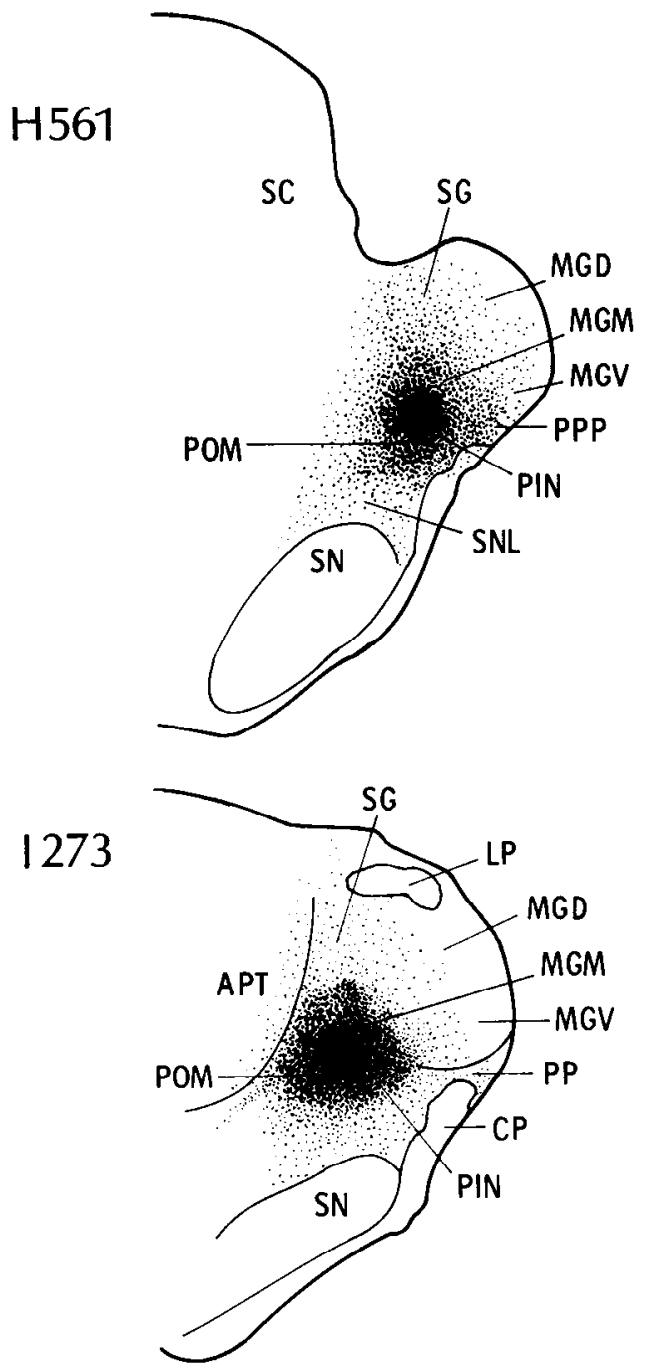

Figure 1. Injections of WGA-HRP into the posterior thalamus. In case $\mathrm{H} 561$ the injection site is centered in the caudal aspects of the MGM, PIN, and POM, whereas in case I273 the rostral portions of these same structures are involved. Both injections produced anterograde transport to the amygdala and striatum (Figs. 2, 3).

\section{Results}

Anterograde transport from the posterior thalamus to the amygdala

WGA-HRP was injected into the posterior thalamus in 17 rats. As previously reported (LeDoux et al., 1985), injections centered in the ventral division of the medial geniculate body (MGB) produced no anterograde transport to the amygdala. However, injections medial to the ventral MGB that included the medial MGB (MGM), the posterior intralaminar nucleus (PIN), and the medial posterior thalamic nucleus (POM), did result in anterograde transport to the amygdala.

In case $\mathrm{H} 561$, the injection site (Fig. 1) involved the caudal aspects of MGM, PIN, and POM. Anterograde transport to the amygdala and striatum is illustrated in Figure 2. Punctate, terminal-like labeling was seen in the dorsal (ALd) and ventral (ALv) parts of the lateral nucleus of the amygdala (AL), basomedial nucleus of the amygdala (ABM), medial nucleus of the amygdala (AM), substantia innominata (SI), and posterior cau- date putamen (CPU). Terminal-like labeling completely surrounded but was conspicuously absent in the round-shaped central core of the central nucleus of the amygdala (ACE). Dorsally and laterally, transport surrounded the ACE and appeared to overlap the intercalated nuclei described by Millhouse (1986). Medially, labeling extended along the lateral edge of the stria terminals (ST) through the medial part of ACE. The amygdalo-striatal transition zone (AST), which separates the dorsal nuclei of the amygdala (ACE and $\mathrm{AL}$ ) from the CPU, was also heavily labeled.

In case I273, the injection (Fig. 1) was located more rostrally in the posterior thalamus but included essentially the same areas as case $\mathrm{H} 561$. Anterograde transport was again seen in AL, AST, $\mathrm{ABM}, \mathrm{AM}, \mathrm{SI}$, medial aspects of $\mathrm{ACE}$, and in the intercalated nuclei dorsal and lateral to ACE (Fig. 3). Although the pattern of transport was similar to case H561, the distribution of transport was shifted somewhat towards the rostral aspects of each labeled structure.

\section{Retrograde transport from the amygdala to the posterior thalamus}

Injections of WGA-HRP were placed into each amygdaloid region labeled in the anterograde experiments described above and retrograde transport to the posterior thalamus was cxamined. Representative injection sites are illustrated in Figure 4.

WGA-HRP was injected into AL in 15 rats. While the size and location of the injection sites varied between cases, all injections that involved AL produced retrograde transport to the posterior thalamus, and specifically to the PIN and, to a lesser extent, the overlying MGM, particularly the ventral part of MGM. Injections of the caudal AL tended to produce more retrogradely labeled neurons in caudal than in rostral areas of the posterior thalamus, whereas injections located in the rostral AL produced more labeling rostrally. Injections involving the dorsal AL produced retrograde labeling in the suprageniculate nucleus (SG) and, to a lesser extent, the lateral posterior thalamic nucleus (LP), as well as in PIN and MGM. Thus, the caudalrostral and dorsal-ventral location of the injection site in $\mathrm{AL}$ produced a corresponding bias in the location of the labeled cells in the posterior thalamus. Locally, anterograde transport was present in the AST region. The injection sites from cases I1 17 and H564 are illustrated in Figure 4 and the retrograde transport results from these are shown in Figure 5.

The soma and dendrites of cells labeled in PIN/MGM following AL injections tended to be densely filled. Soma diameter varied between $10-25 \mu \mathrm{m}$, with most cells having soma in the 10-15 $\mu \mathrm{m}$ range.

Injections targeted for AST were made in 11 cases. In many of these, the injection sites spread ventrally to the ACE. In 3 cases, however, the ventral border of the injection site remained confined to the AST region and to the striatum above. In these cases, the pattern of transport was essentially the same as in cases with injections of the lateral amygdala. A representative injection of AST (case I225) is shown in Figure 4 and the pattern of retrograde transport is illustrated in Figure 5. Locally, retrograde transport was present in the lateral amygdala, thus confirming the projection from AL to AST, as described above. Cell size was similar to that described for AL injections.

Injections of the medial and/or basomedial nuclei of the amygdala were made in 10 rats. In contrast to injections of the $\mathrm{AL}$ and ASI, these injections produced no labeling in areas of the MGB or in the PIN. However, labeled cells were present 


\section{H561}
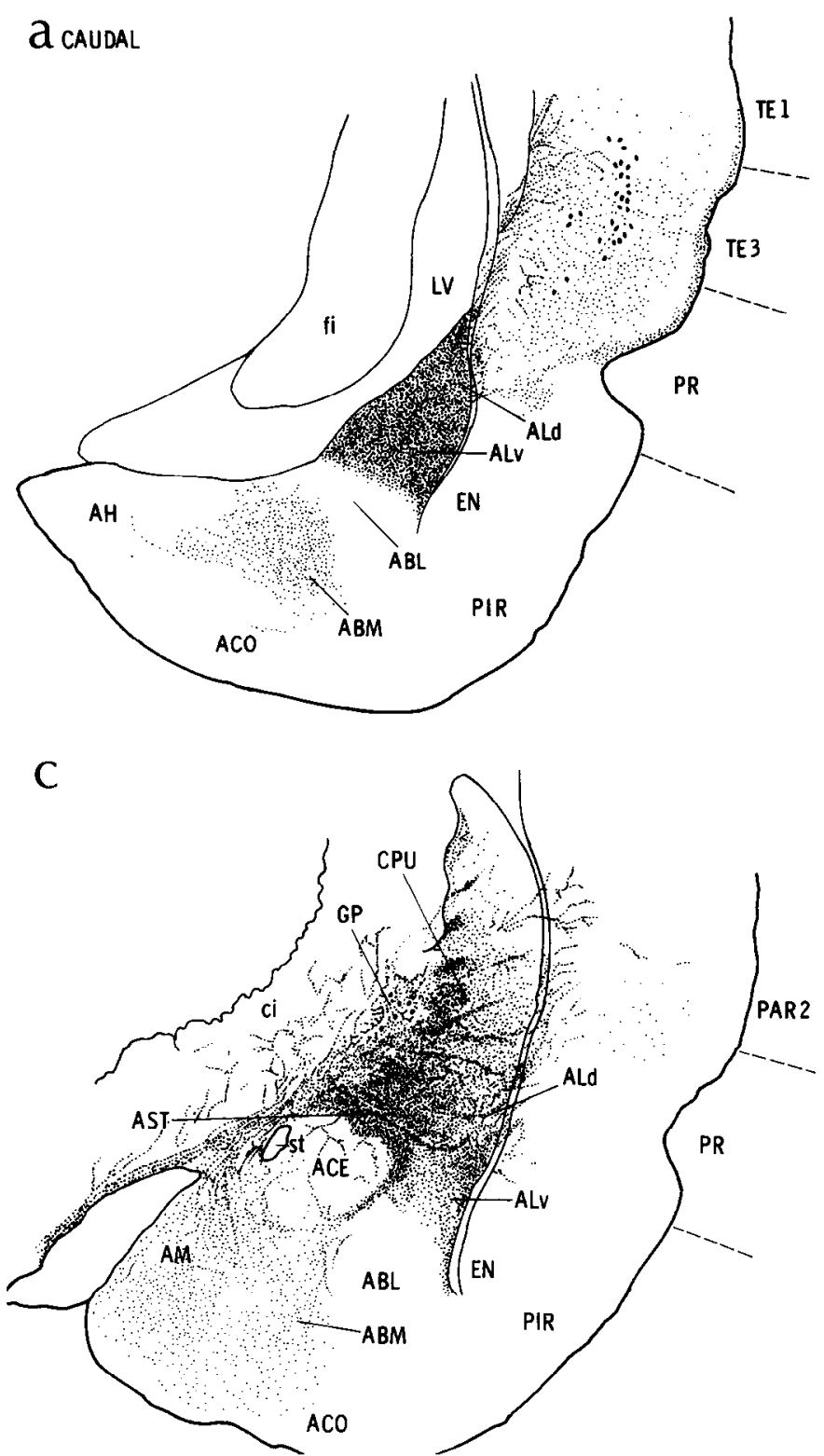
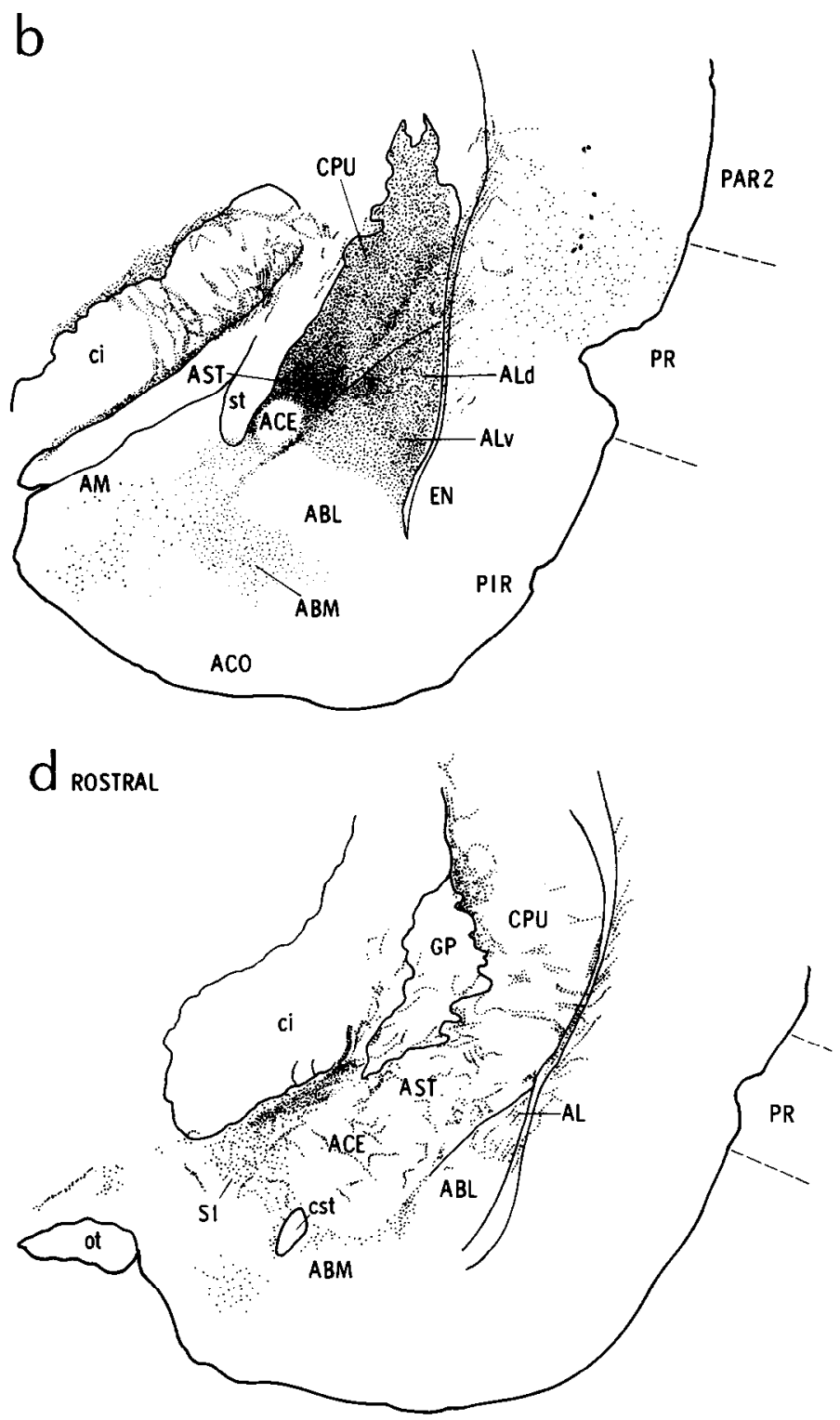

Figure 2. Anterograde transport to the amygdala and striatum following injection of WGA-HRP into the caudal posterior thalamus in case H561. The injection site is depicted in Figure 1.

more medially in POM, which is wedged between the lateral border of the anterior pretectal nucleus (APT) and the medial border of the MGM and PIN. The injection site in case I218 is illustrated in Figure 4 and transport to the posterior thalamus is shown in Figure 6. Labeled cells tended to be somewhat smaller (varying between 5 and $20 \mu \mathrm{m}$ ) than in cases with $\mathrm{AL}$ and AST injections. Also, the density of labeling was less in these cases than in cases with AL and AST injections, with dendritic filling being uncommon.

Although the central core of the ACE did not contain anterograde transport in the above studies, the areas immediately surrounding it (including the medial ACE and the intercalated nuclei dorsal and lateral to ACE) did. Therefore, injections were targeted to include the central core of ACE as well as surrounding structures. Retrograde transport to the posterior thalamus was present in 11 of 14 cases. Typically, retrogradely filled neurons were clustered in POM. Transport to the MGM, SG, and PIN was present mainly in cases where the injection site included AST or AL. Injections that included the central core of the ACE and ventromedially located structures consistently labeled cells in POM. Injections located in the rostral part of ACE produced more labeling in rostral than in caudal areas of the posterior thalamus and injections located caudally in the central amygdala produced more labeling in the caudal than in the rostral areas. However, since PIN extends further caudally than does POM, in no case did labeling produced by injections of ACE and adjacent areas extend as far caudally as labeling produced by injections of AL or AST. Some rostrally located injections included the SI and produced labeling in the rostral extent of POM. Results from 2 cases (I227, H439) with ACE injections are 

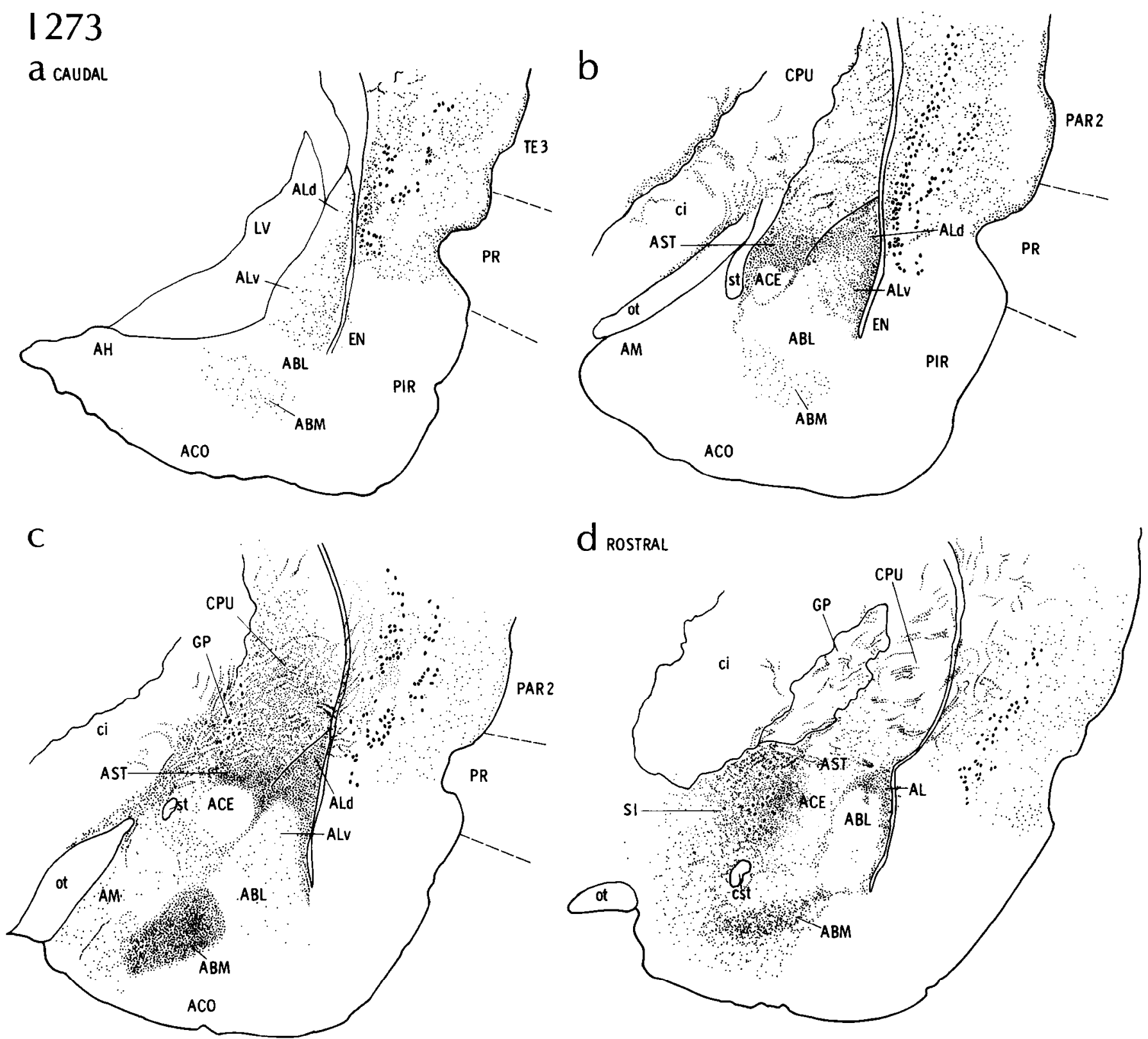

Figure 3. Anterograde transport to the amygdala and striatum following injection of WGA-HRP into the rostral posterior thalamus in case I273. The injection site is depicted in Figure 1.

shown in Figure 6. The injection sites are illustrated in Figure 4. Cell size and label density were similar to that described above for injections of the medial and basomedial amygdala.

In 2 cases injections involved the basolateral amygdala ( $A B L$ ), ventral to AL. Consistent with the anterograde results described above, these injections produced little or no labeling in the posterior thalamus.

\section{Relationship of the thalamic neurons that project to the} amygdala to the thalamic projection field of the inferior colliculus

The thalamic projection field of the inferior colliculus includes the ventral, dorsal, and medial division of the MGB, SG, PIN, peripeduncular nucleus (PP), posterior limitans nucleus, and lateral part of the subparafascicular nucleus (SPFL) (LeDoux et al., 1985, 1987a). In the studies reported here, then, AL and AST would be the primary recipients of acoustic inputs, as these are the structures that receive the bulk of the projections from thalamic areas that, in turn, receive inputs from the inferior colliculus. This colliculo-thalamo-amygdaloid projection sequence, and particularly the projection sequence to $\mathrm{AL}$, was corroborated in 2 ways.

First, we placed injections of WGA-HRP into the PIN/MGM region and examined retrograde transport to the inferior colliculus and anterograde transport to the amygdala. Case I209, which had an injection located in the caudal aspects of PIN, is representative (Fig. 7). In the inferior colliculus, retrogradely labeled cells were present in the external and pericentral nuclei (ICX and ICP, respectively) and in the dorsal cortex. These cells formed a rim around the lateral, dorsal, and medial edges of 
1117
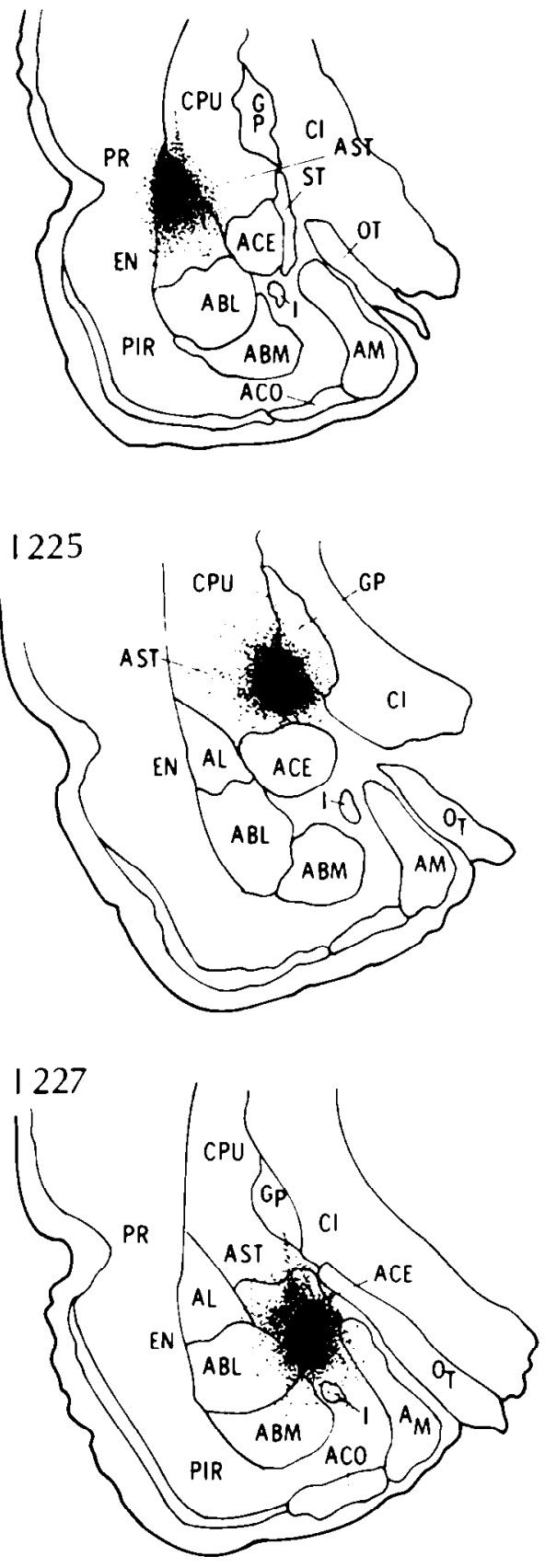

H564
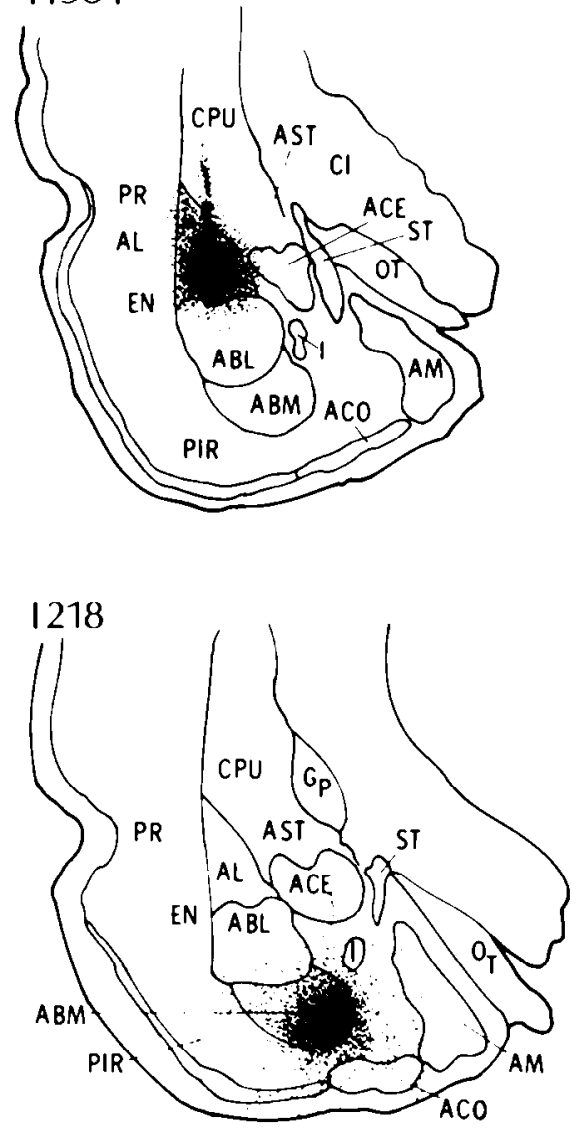

H439

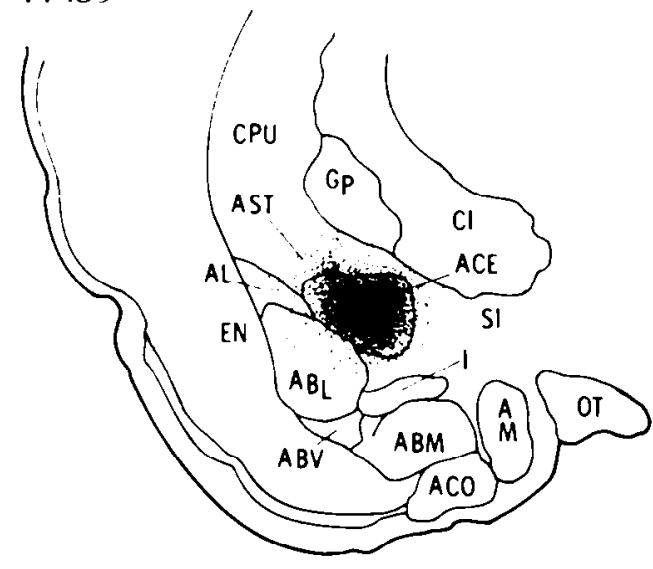

Figure 4. Injections of WGA-HRP into areas of the amygdala that were anterogradely labeled following injections in the posterior thalamus (see Figs. 2 and 3 for anterograde transport to the amygdala). 1117 . injection of the lateral amygdala, particularly the dorsal lateral amygdala; $H 564$. injection of the lateral amygdala; 1225 , injection of the amygdalo-striatal transition zone above the central amygdala; $I 218$, injection of the basomedial amygdala: 1227 . injection of the ventromedial central amygdala: H439. injection of the rostral central amygdala. the inferior colliculus. The central nucleus of the inferior colliculus (ICC), by contrast, had only a few scattered labeled cells. Labeled cells were also present in the dorsal and ventral nuclei of the lateral lemniscus and in the sagulum nucleus. Anterograde transport to the amygdala was essentially the same as that described for case H561 (see Fig. 2). Thus, WGA-HRP injected into PIN/MGM is transported retrogradely to the inferior colliculus and anterogradely to the lateral amygdala.

Second, we examined the location of retrogradely labeled neurons following injection of FG in the lateral amygdala with respect to the pattern of anterograde transport of WGA-HRP following injection in the inferior colliculus. The pattern of re- trograde transport of FG from the lateral amygdala to the PIN, MGM, and SG was the same as in cases with injections of WGAHRP into lateral amygdala (see Fig. 4). Anterograde transport of WGA-HRP from the inferior colliculus to the posterior thalamus was similar to that described in previous publications (LeDoux et al., 1985, 1987a). As shown in Figure 8, retrogradely labeled cells in PIN are located within the field of anterograde transport.

\section{Discussion}

Studies of several different species have shown that areas of the posterior thalamus give rise to projections to the amygdala (Eb- 
1117
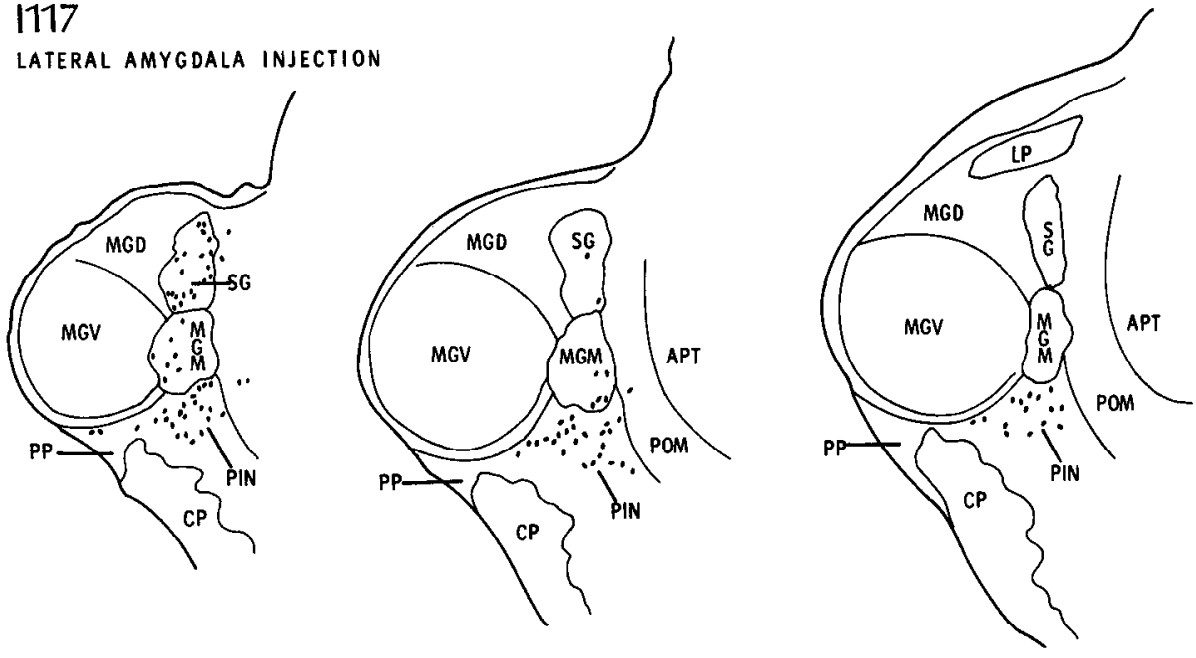

$\mathrm{H} 564$

LATERAL AMYGDALA INJECTION
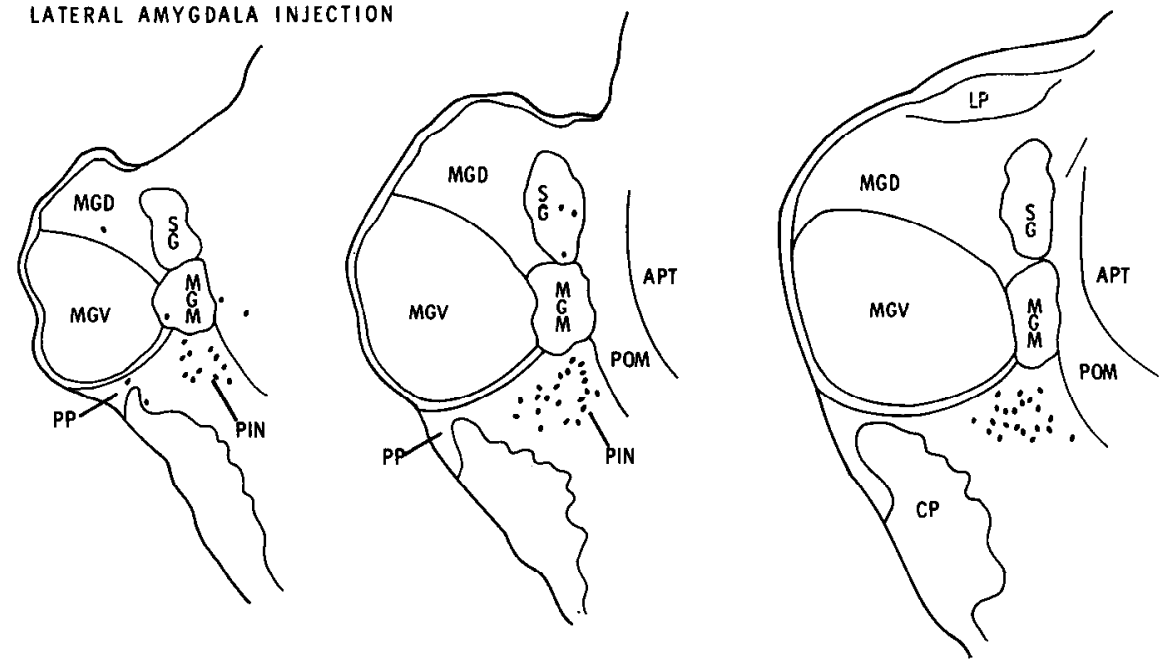

\section{5}

Figure 5. Retrograde transport to the posterior thalamus following injection of WGA-HRP into the lateral nucleus of the amygdala (cases $I 117$ and $H 564$ ) and the amygdalo-striatal transition zone (case I225). Injection sites are depicted in Figure 4. Note that the retrogradely labeled cells are concentrated in the PIN, MGM, and SG. Compare with injections of the central and basomedial nuclei, which produce labeled cells primarily in the POM (see Fig. 6).
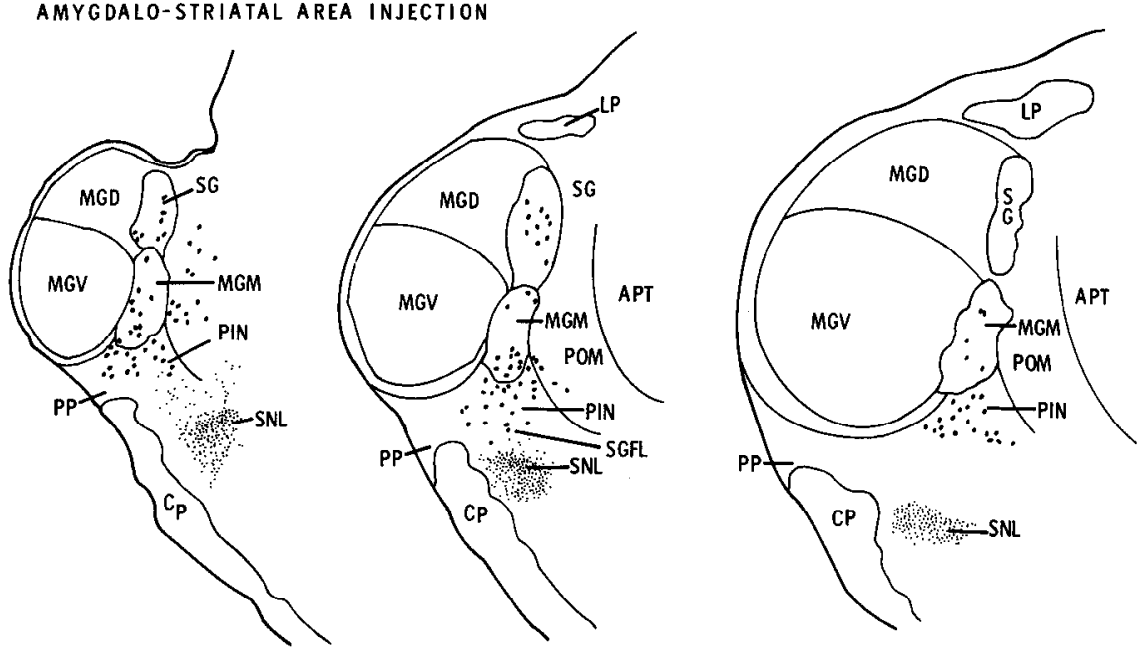

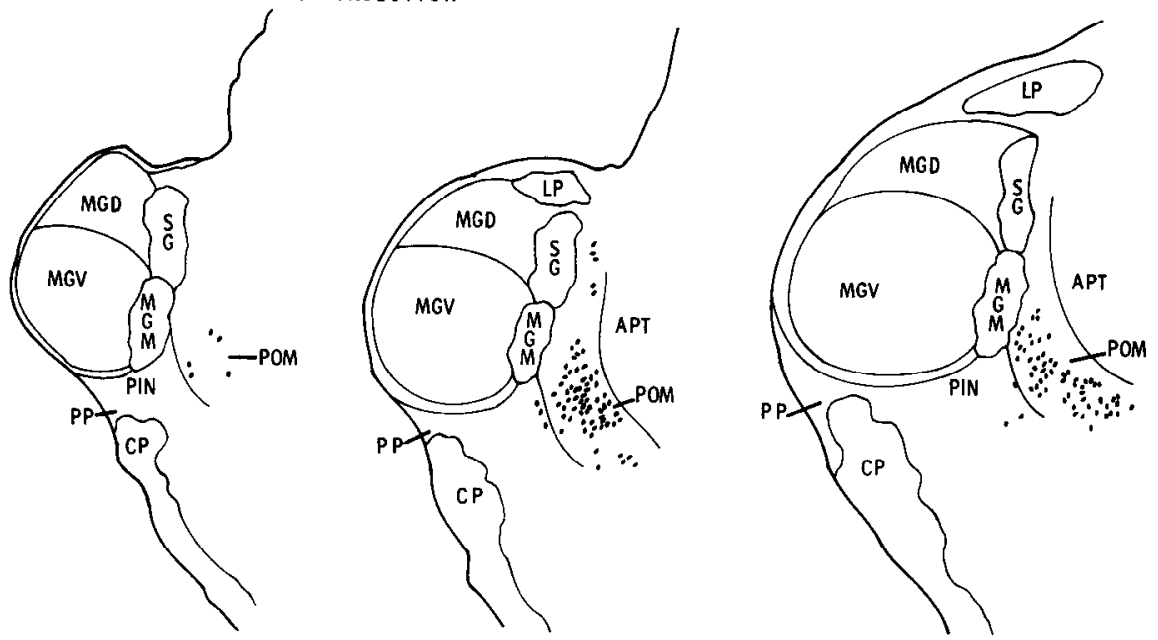

\section{$\mathrm{H} 439$}

CENTRAL AMYGDALA INJECTION
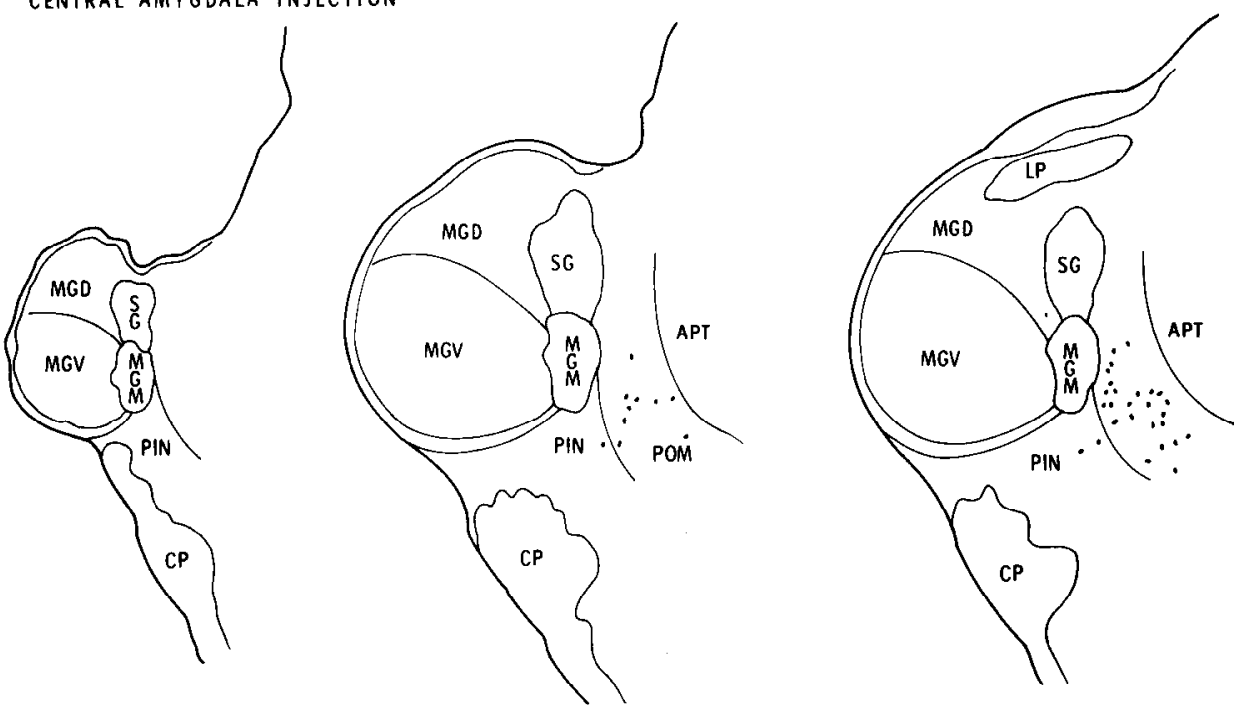

1227

CENTRAL AMYGOALA INJECTION
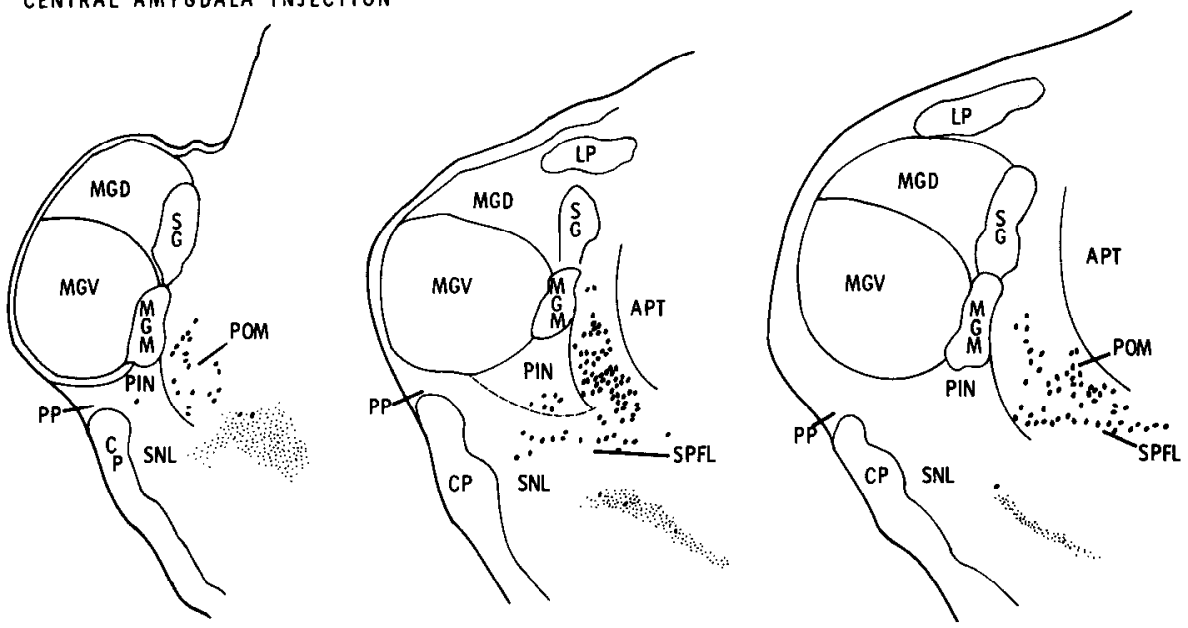

Figure 6. Retrograde transport to the posterior thalamus following injection of WGA-HRP into the basomedial (case I218) and central (cases $I 227$ and $H 439$ ) nuclei of the amygdala. Note that the retrogradely labeled cells are concentrated in the POM. The injection sites are depicted in Figure 4. Compare the results with injections of the lateral nucleus of the amgydala and the amygdalo-striatal transition zone, which produce retrograde labeling in the PIN, MGM, and SG, but not in POM (see Fig. 5). 
a
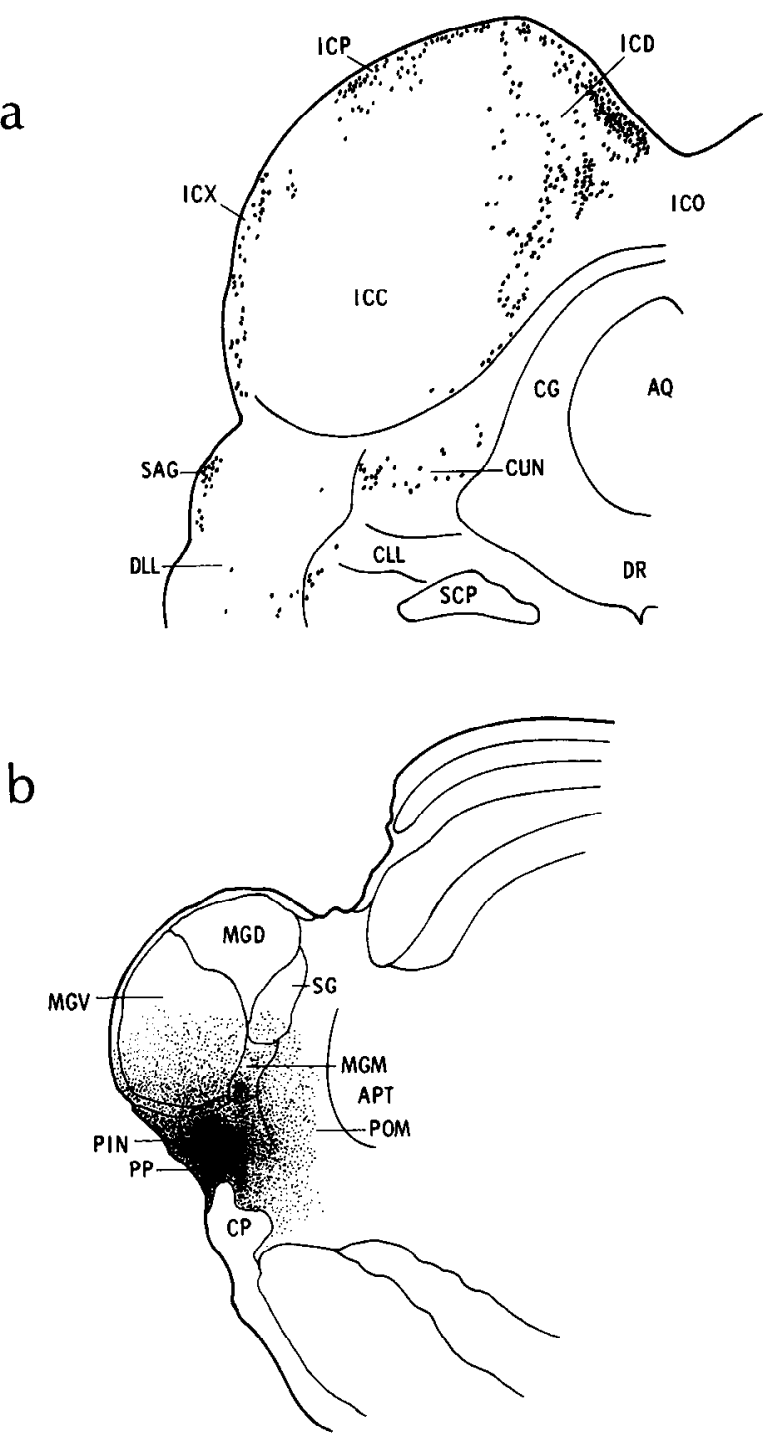

C

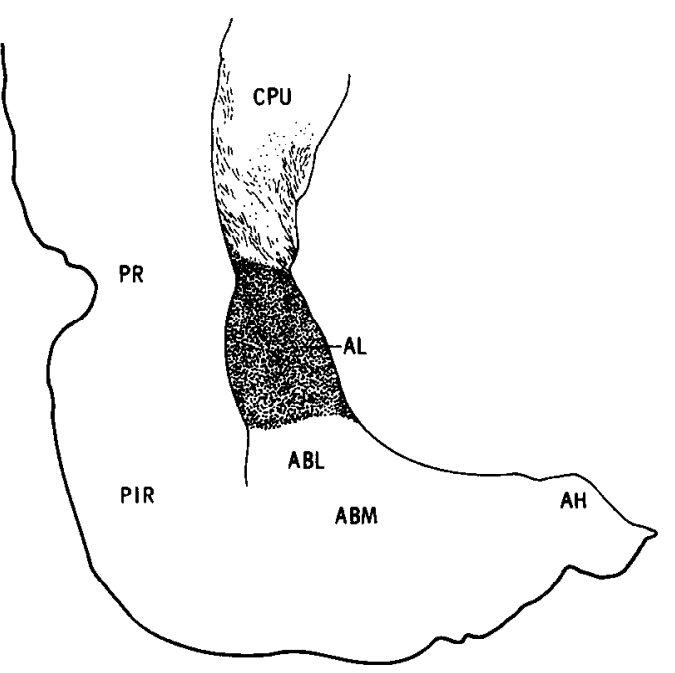

Figure 7. Retrograde transport to the inferior colliculus (a) and anterograde transport to the amygdala $(c)$ following an injection of WGAHRP into the PIN region $(b)$. Although the injection spread beyond the borders of PIN and included the ventral MGB, the fact that the central nucleus of the inferior colliculus contained few labeled cells indicates that diffusion to the ventral MGB was not effective in supporting axonal ner, 1969; Graybiel, 1972; Veening, 1978; Ottersen and BenAri, 1979; Turner and Herkenham, 1981; Russchen, 1982; LeDoux et al., 1984, 1985; Kudo et al., 1986, 1989). These projections have been implicated in the processing of the affective properties of auditory stimuli (for review, see LeDoux, $1986,1987)$. The aim of the present study was to identify possible auditory input areas of the amygdala by determining which regions of the amygdala receive inputs from thalamic areas that, in turn, receive acoustic afferents.

Injections of WGA-HRP into the MGB and adjacent structures resulted in anterograde transport to several different areas of the amygdala, including AL, AST, ABM, AM, SI, and ventromedial ACE. Injection of WGA-HRP into AL or AST consistently resulted in a concentration of retrogradely labeled cells in the MGM and PIN. In contrast, retrograde transport was concentrated in POM following injections of ABM, AM, SI, and ACE.

MGM, PIN, and POM are arranged in a triangular conformation in the posterior thalamus (LeDoux et al., 1985, 1987a). Some studies of retrograde transport following amygdala injections have referred to the entire complex as the MGM. For example, Ottersen and Ben-Ari (1979) show a photomicrograph (their figure 16) of a group of retrogradely labeled cells located lateral to the anterior pretectal nucleus and produced by an HRP injection in ACE. Although they refer to this cell group as part of the MGM, the cells are actually located in the region we refer to in this report as POM. The distinction between POM and $\mathrm{PIN} / \mathrm{MGM}$ is readily seen by comparing the results of injections in AL or AST with ACE or ABM (see Figs. 4-6). AL and AST receive afferents from $P I N$ and $M G M$, whereas $A C E$ and $A B M$ receive afferents from the medially adjacent POM. Moreover, cells in POM are, on the average, slightly smaller than cells in MGM/PIN.

In an earlier report, we illustrated retrograde transport to an area labeled PIN following an injection centered on ACE, but spreading to adjacent areas (LeDoux et al., 1985). At that time, we did not fully appreciate the distinction between PIN and POM, nor were we as cognizant of the importance of the differential inputs to the lateral and central nuclei of the amygdala. In reexamining this case in light of our improved understanding of the organization of the area, it appears that cells in both PIN and POM were labeled. Given the results of the present study, which was specifically aimed at addressing the local rather than global organization of thalamo-amygdala projections, we feel confident that labeling in PIN in this case reflected the spread of the injection to AL or AST.

The cytoarchitectural organization of the posterior thalamus in mammals is complex and has been a source of much confusion in the literature (see Jones and Burton, 1974; Neylon and Haight, 1983; Winer and Morest, 1983; Winer et al., 1988). As discussed by Jones and Burton (1974), the term "posterior group" was first introduced by Rose and Woolsey (1958) to include illdefined cell groups of the posterior thalamus, including the medial or magnocellular division of the MGB, SG, and other areas that tended to blend with the thalamo-cortical sensory relay areas of the auditory, somatosensory, and visual systems. However,

transport. Anterograde transport is only illustrated for the caudal level of the amygdala, where the lateral nucleus is completely filled. Anterograde transport to the remainder of the amygdala was similar to that illustrated in Figure 2 for case $\mathrm{H} 561$. 

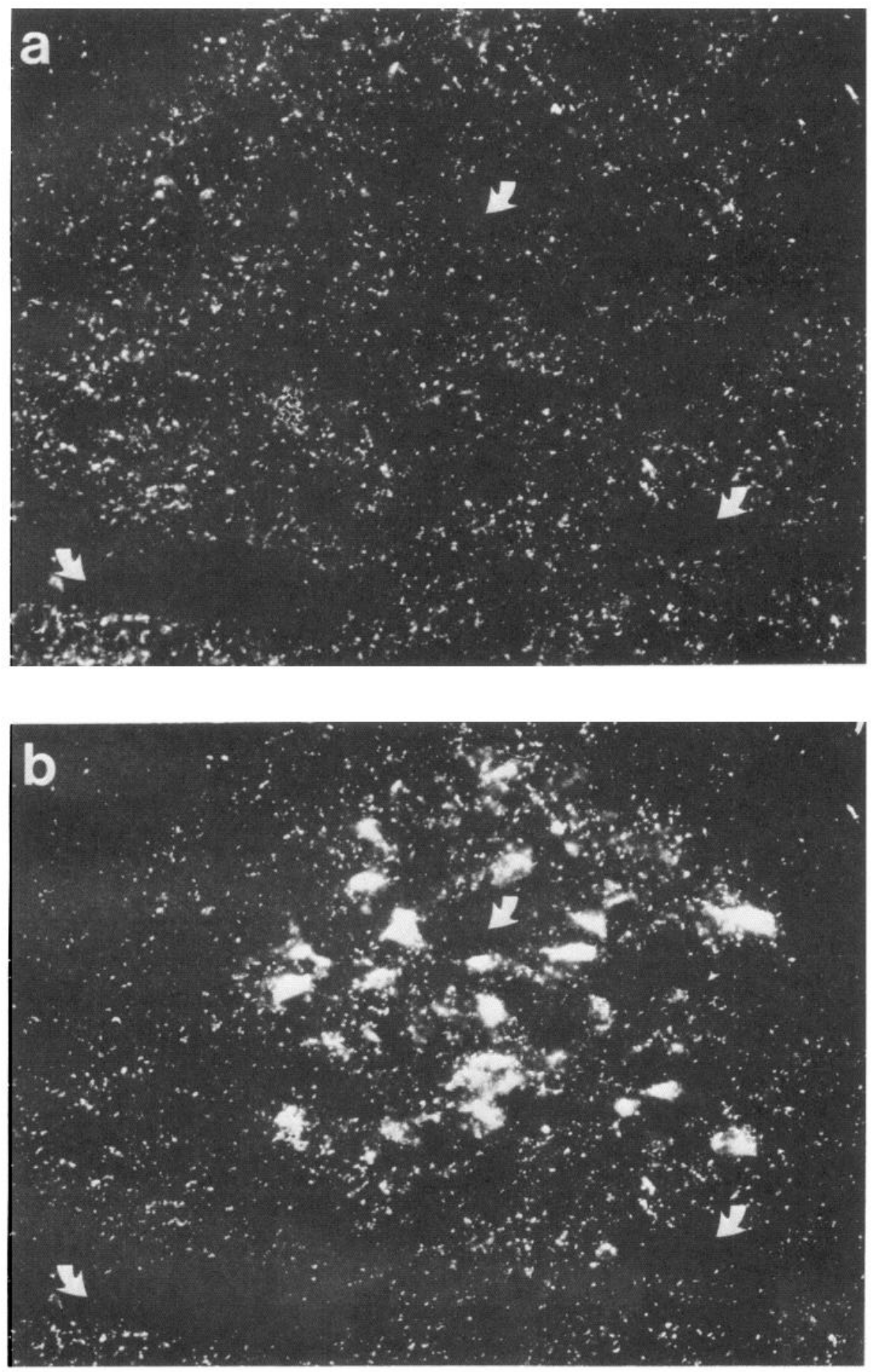

Figure 8. Retrograde transport of Fluoro-Gold to neurons in the PIN that are surrounded by anterograde transport of WGA-HRP from the inferior colliculus, thus confirming the colliculo-thalamo-amgydala relay. Anterograde transport to and from the inferior colliculus to the PIN is illustrated in $a$. In $b$, FG labeling of neurons in PIN is visualized, through UV fluorescence optics, over the anterogradely labeled field. The white arrows mark the location of blood vessels for orientation. as new data emerged over the years, particularly data concerning connectivity, one by one different components have been separated out, leaving the term posterior group to refer to what remained. Findings reported in this and previous studies (LeDoux et al., 1985, 1987a) indicate that the area just ventral to the MGM receives afferents from the inferior colliculus and thus might, in distinction to other, more medially located areas of the posterior group, be considered part of the acoustic thalamus. We (LeDoux et al., 1985) referred to this region as the PIN or posterior intralaminar nucleus. ${ }^{3}$ The area medial to PIN and lateral to the anterior pretectal nucleus (APT) receives somatic afferents from the spinal cord but does not receive acoustic afferents from the inferior colliculus (LeDoux et al., 1987a). In

${ }^{3}$ The term posterior intralaminar nucleus (PIN) was suggested to us by Dr. D. K. Morest on the basis of his studies, with J. A. Winer and I. T. Diamond, of the opossum thalamus. We used this term in an earlier paper (LeDoux et al., 1985). Winer et al. (1988) later published their observations on the posterior intralaminar system in the opossum. 
an attempt to be consistent with the parcellation of the cat posterior thalamus, which recognizes a medial area called POM that receives somatic but not acoustic afferents (Jones and Powell, 1971; Graybiel, 1972; Philips and Irvine, 1979), we refer to this region between PIN and APT in the rat as POM. Our POM may represent a caudal extension of the more rostral POM of Donaghue et al. (1979) and Jones (1983).

The differentiation between amygdala areas that do and do not receive acoustic afferents has important implications for understanding the neural pathways mediating emotional (fear) conditioning. It is well recognized that ACE is a critical link in the emotional conditioning circuit (Kapp et al., 1979, 1984; Gentile et al., 1986; Hitchcock and Davis, 1986; Iwata et al., 1986). ACE appears to direct amygdala outputs to areas that control the expression of different (i.e., behavioral, autonomic, humoral) responses (Smith et al., 1980; Kapp et al., 1984; LeDoux et al., 1988). Our finding that emotional conditioning can be mediated by subcortical auditory projections to the amygdala (LeDoux et al., 1984, 1986a, b; Iwata et al., 1986), together with the observation that that IIRP injected into ACE is retrogradely transported to the posterior thalamic areas bordering the MGB (Veening, 1978; Ottersen and Ben-Ari, 1979; LeDoux et al., 1985), suggested that a direct acoustic relay to ACE (central core and surrounding, associated nuclei, including the medial ACE and intercalated nuclei) from the thalamus might mediate emotional conditioning (Iwata et al., 1986). However, the present results showing that $A C E$ is not a recipient of fibers from acoustic processing areas of the thalamus question this view and suggest instead that AL or AST might be the sensory interface of the amygdala. Recent behavioral studies, inspired by these anatomical observations have, in fact, shown that lesions confined to $\mathrm{AL}$ are quite effective in preventing the conditioning of fear responses to acoustic stimuli (Cicchetti et al., 1987; LeDoux et al., 1990). Neurons in AL may constitute an interface network that allows sensory inputs to access the emotional response mechanisms organized through ACE.

$\mathrm{AL}$ also receives afferents from sensory processing areas of the neocortex (Whitlock and Nauta, 1956; Jones and Powell, 1970; Herzog and van Hoesen, 1976; Aggleton et al., 1980; Turner et al., 1980; Amaral, 1987), and there is evidence that within a given sensory modality, such as audition, cortical and thalamic sensory projections converge in AL (LeDoux et al., 1987b; Kudo et al., 1989). Although the thalamic inputs are not likely to provide a very accurate or detailed representation of the eliciting stimulus, they reach the amygdala somewhat earlier, due to the additional synaptic relays imposed by transmission through the cortex. Thalamic sensory projections to the amygdala may therefore offer temporal processing advantages which could be especially important in situations requiring the rapid organization of defensive or other emotional responses. However, since the stimulus representation transmitted by thalamic neurons that project to the amygdala is likely to be far inferior to that transmitted by cortical relays, it is important that the activation of the amygdala by the cortex be able to operate on the same circuits as the thalamic input. Emotional responses initiated by thalamic systems could thereby be modified, as necessary, by more refined signals arriving from cortex.

Inputs from other sensory systems also reach the amygdala directly from the thalamus. MGM, PIN, and POM each receive spinal afferents in the rat (LeDoux et al., 1987a) and may therefore transmit somatic inputs to the amygdala. Also, behavioral studies show that in the absence of visual cortex, rats can be conditioned to visual stimuli (LeDoux et al., 1989) but that in the absence of the amygdala they cannot (Davis et al., 1987). Subcortical visual inputs to the amygdala thus appear to exist. In the present studies we found cells, albeit few, labeled in the lateral posterior thalamic nucleus, a visual relay structure, following AL injections. Another possibility for a visual thalamoamygdala relay is $\mathrm{SG}$, which may have a role in vision as well as audition (Neylon and Haight, 1983).

It is tempting to think of thalamo-amygdala projections as accessory circuits of the more classically defined thalamo-cortico-amygdala projections. However, in phylogenetically primitive vertebrates, in which the neocortex is poorly developed, thalamic projections to noncortical forebrain areas predominatc (Ebner, 1969; Nauta and Karten, 1970; Kudo et al., 1986). The thalamo-amygdala projections of mammals, therefore, may be an evolutionarily primitive emotional processing channel.

It has been suggested that thalamo-amygdala sensory projections do not exist in primates (Kudo et al., 1986). However, in monkeys, AL receives a projection from the PP (Jones et al., 1976; Aggleton et al., 1980; Mehler, 1980). The primate PP has the same morphological relationship to the MGB as the PIN does in the rat, and fibers from the inferior colliculus terminate in the primate PP (Moore and Goldberg, 1966), as well as in the rat PIN (LeDoux et al., 1987a). Acoustic inputs may therefore reach the amygdala directly from the thalamus in primates, despite the fact that neurons within the MGB proper do not project to the amygdala in primates.

In conclusion, the results of the present studies identify pathways through which acoustic inputs from the thalamus might reach the amygdala directly, bypassing the neocortex. These thalamo-amygdala projections may be evolutionarily primitive sensory channels that play an important role in the processing of stimuli with emotional significance.

\section{Appendix}

Abbreviations

ABM, amygdala, basomedial nucleus;

ABL, amygdala, basolateral nucleus;

ACE, amygdala, central nucleus;

$\mathrm{ACO}$, amygdala, cortical nucleus;

$\mathrm{AH}, \quad$ amygdalo-hippocampal area;

AL, amygdala, lateral nucleus;

ALd, amygdala, dorsal lateral nucleus;

ALv, amygdala, ventral lateral nucleus;

AM, amygdala, medial nucleus;

APT, anterior pretectal nucleus;

$\mathrm{AQ}, \quad$ cerebral aqueduct;

AST, amygdalo-striatal transition zone;

CG, central gray region;

CLL, commissure of the lateral lemniscus;

CUN, cuneiform nucleus;

$\mathrm{CI}$ internal capsule;

CP, cerebral peduncule;

CPU, caudate putamen;

DLL, dorsal nucleus of the lateral lemniscus;

DR, dorsal raphe nucleus;

EN, entorhinal cortex;

fi, fimbria;

GP, globus pallidus;

I, intercalated nuclei of the amygdala;

ICC, central nucleus of the inferior colliculus;

ICD, dorsal cortex of the inferior colliculus;

ICO, commissural area of the inferior colliculus;

ICP, pericentral nucleus of the inferior colliculus;

ICX, external nucleus of the inferior colliculus; 
LP, lateral posterior thalamic nucleus;

LV, lateral ventricle;

MGD, medial geniculate body, dorsal nucleus;

MGM, medial geniculate body, medial nucleus;

MGV, medial geniculate body, ventral nucleus;

OT, optic tract;

ot, optic tract;

PAR2, parietal cortex, area 2;

PIN, posterior intralaminar nucleus;

PIR, piriform cortex;

POM, posterior thalamic complex, medial group;

$\mathrm{PP}, \quad$ peripeduncular nucleus;

PR, perirhinal corlex;

SC, superior colliculus;

SG, suprageniculate nucleus;

SI, substantia innominata;

SN, substantia nigra:

SPFL, subparafascicular nucleus, lateral part;

ST, stria terminalis;

st, stria terminalis;

TE1, temporal cortex, area 1; and

TE2, temporal cortex, area 2.

\section{References}

Aggleton, J. P., M. J. Burton, and R. E. Passingham (1980) Cortical and subcortical afferents to the amygdala of the rhesus monkey ( $\mathrm{Ma}$ caca mulatta). Brain Res. 190: 347-368.

Amaral, D. (1987) Memory: Anatomical organization of candidatc brain regions. In Handbook of Physiology, Sect. 1: Neurophysiology, Vol. 5: Higher Functions of the Brain, F. Plum, ed., pp. 211-294, American Physiological Society, Bethesda, MD.

Cicchetti, P., J. E. LeDoux, and D. J. Reis (1987) The lateral amygdaloid nucleus: Sensory interface of the amygdala in fear conditioning. Soc. Neurosci. Abstr. (in press).

Davis, M., J. M. Hitchcock, and J. B. Rosen (1987) Anxiety and the amygdala: Pharmacological and anatomical analysis of the fear-potentiated startle paradigm. In The Psychology of Learning and Motivation, G. H. Bower, ed., pp. 263-305, Academic, San Diego.

Donoghue, J. P., K. L. Kerman, and F. F. Ebner (1979) Evidence for two organizational plans within the somatic sensory-motor cortex of the rat. J. Comp. Neurol. 183: 647-664.

Ebner, F. (1969) A comparison of primitive forcbrain organization in metatherian and eutherian mammals. Ann. NY Acad. Sci. 167:241257.

Gentile, C. G., T. W. Jarrel, A. Teich, P. M. McCabe, and N. Schneiderman (1986) The role of amygdaloid central nucleus in the retention of differential Pavlovian conditioning of bradycardia in rabbits. Behav. Brain Res. 20: 263-273.

Graybiel, A. M. (1972) Some ascending connections of the pulvinar and nucleus lateralis posterior of the thalamus in the cat. Brain Res. 44: $99-125$.

Herzog, A. G., and G. W, van Hoesen (1976) Temporal neocortical afferent connections to the amygdala in the rhesus monkey. Brain Res. 115: 57-69.

Hitchcock, J. M., and M. Davis (1986) Amygdala lesions block fearenhanced startle using either visual or auditory conditioned stimuli. Soc. Neurosci. Abstr. 12: 752.

Iwata, J., J. E. LeDoux, and D. J. Reis (1986) Destruction of intrinsic neurons in the lateral hypothalamus disrupts cardiovascular but not behavioral conditioned emotional responses. Brain Res. 368: 161166.

Jones, E. G. (1983) The thalamus. In Chemical Neuroanatomy, P. Emson, ed., pp. 257-293, Raven, New York.

Jones, E. G., and H. Burton (1974) Cytoarchitecture and somatic sensory connectivity of thalamic nuclei other than the ventrobasal complex in the cat. J. Comp. Neurol. 154: 395-432.

Jones, E. G., and T. P. S. Powell (1970) An anatomical study of converging sensory pathways within the cerebral cortex of the monkey. Brain 93: 793-820.

Joncs, E. G., H. Burton, C. B. Saper, and L. W. Swanson (1976) Midbrain, diencephalic and cortical relationships of the basal nucleus of Meynert and associated structures in primates. J. Comp. Neurol. 167: $385-420$.

Kapp, B. S., R. C. Frysinger, M. Gallagher, and J. R. Haselton (1979)
Amygdala central nucleus lesions: Effects on heart rate conditioning in the rabbit. Physiol. Behav. 23: 1109-1117.

Kapp, B. S., J. P. Pascoe, and M. A. Bixler (1984) The amygdala: A neuroanatomical systems approach to its contributions to averse conditioning. In The Neuropsychology of Memory, N. Buttlers and L. R. Squires, eds., pp. 473-488, Guilford, New York.

Kudo, M., K. K. Glendenning, S. B. Frost, and R. S. Masterson (1986) Origin of mammalian thalamocortical projections. I. Telencephalic projection of the medial geniculate body in the opossum (Didelphis virginiana). J. Comp. Neurol. 245: 176-197.

Kudo, M., L. M. Aitkin, and J. E. Nelson (1989) Auditory forebrain organization of an Australian marsupial, the northern native cat (Dasyurus hallucatus). J. Comp. Neurol. 279: 28-42.

LeDoux, J. E. (1986) Sensory systems and emotion: a model of affective processing. Integr. Psychiatry 4: 237-238.

LeDoux, J. E. (1987) Emotion. In Handbook of Physiology, Nervous System, Vol. 5, Higher Function, F. Plum, vol. ed., V. Mountcastle, sect. ed., pp. 419-459, American Physiological Society, Washington, D.C.

LeDoux, J. E., A. Sakaguchi, and D. J. Reis (1984) Subcortical efferent projections of the medial geniculate nucleus mediate emotional responses conditioned by acoustic stimuli. J. Neurosci. 43: 683-698.

LeDoux, J. E., D. A. Ruggiero, and D. J. Reis (1985) Projections to the subcortical forebrain from anatomically defined regions of the medial geniculate body in the rat. J. Comp. Neurol. 242: 182-213.

LeDoux, J. E., J. Iwata, D. Pearl, and D. J. Reis (1986a) Disruption of auditory but not visual learning by destruction of intrinsic neurons in the medial geniculate body of the rat. Brain Res. 371: 395-399.

LeDoux, J. E., A. Sakaguchi, J. Iwata, and D. J. Reis (1986b) Interruption of projections from the medial geniculate body to an archineostriatal field disrupts the classical conditioning of emotional responses to acoustic stimuli. Neuroscience 17: 615-627.

LeDoux, J. E., D. A. Ruggiero, R. Forrest, R. Stornetta, and D. J. Reis (1987a) Topographic organization of convergent projections to the thalamus from the inferior colliculus and spinal cord in the rat. J. Comp. Neurol. 264: 123-146.

LeDoux, J. E., C. Farb, D. A. Ruggiero, and D. J. Reis (1987b) Thalamic and cortical auditory pathways converge in the rat amygdala. Soc. Neurosci. Abstr. 13: 1467.

LeDoux, J. E., J. Iwata, P. Cicchetti, and D. J. Reis (1988) Different projections of the central amygdaloid nucleus mediate autonomic and behavioral correlates of conditioned fear. J. Neurosci. 8: 2517-2529.

LeDoux, J. E., L. Romanski, and A. Xagoraris (1989) Indelibility of subcortical emotional memories. J. Cog. Neurosci. (in press).

LeDoux, J. E., P. Cicchetti, A. Xagoraris, and L. Romanski (1990) The lateral amygdaloid nucleus: Sensory interface of the amygdala in fear conditioning. J. Neurosci. 10: 1062-1069.

Mehler, W. R. (1980) Subcortical afferent connections of the amygdala in the monkey. J. Comp. Neurol. 190: 733-762.

Mesulam, M.-M. (1978) Tetramethylbenzidine for horseradish peroxidase neurohistochemistry: A non-carcinogenic blue reaction product with superior sensitivity for visualizing neural afferents and efferents. J. Histochem. Cytochem. 26: 106-117.

Millhouse, O. E. (1986) The intercalated cells of the amygdala. J. Comp. Neurol. 247: 246-271.

Moore, R. Y., and J. M. Goldberg (1966) Ascending projections of the inferior colliculus in the monkey. Exp. Neurol. 14: 429-438.

Nauta, W. J. H., and H. J. Karten (1970) A general profile of the vertebrate brain, with sidelights on the ancestry of cerebral cortex. In The Neurosciences: Second Study Program, F. O. Schmidt, pp. 7-26, Rockefeller University Press, New York.

Neylon, L., and J. R. Haight (1983) Neocortical projections of the suprageniculate and posterior thalamic nuclei in the marsupial brushtailed possum, Trichosurus vulpecula (Phalangeridae), with a comparative commentary on the organization of the posterior thalamus in marsupial and placental mammals. J. Comp. Neurol. 217: 357375.

Ottersen, O. P., and Y. Ben-Ari (1979) Afferent connections to the amygdaloid complex of the rat and cat: Projections from the thalamus. J. Comp. Neurol. 187: 401-424.

Phillips, D. P., and D. R. Irvine (1979) Acoustic input to single neurons in pulvinar posterior complex of cat thalamus. J. Neurophysiol. 42: 123-136.

Ruse, J. E., and C. N. Woolsey (1958) Cortical connections and functional organization of thalamic auditory system of the cat. In Biolog- 
ical and Biochemical Bases of Behavior, H. F. Harlow and C. N. Woolsey, eds., U. Wisconson Press, Madison.

Russchen, F. T. (1982) Amygdalopetal projections in the cat. II. Subcortical afferent connections. A study with retrograde tracing techniques. J. Comp. Neurol. 207: 157-176.

Schmued, L., and J. H. Fallon (1986) Fluoro-Gold: A new fluorescent retrograde tracer with numerous unique properties. Brain Res. 377: 147-154.

Smith, O. A., C. A. Astley, J. L. DeVito, J. M. Stein, and R. E. Walsh (1980) Functional analysis of hypothalamic control of the cardiovascular responses accompanying emotional behavior. Fed. Proc. 29 2487-2494.

Turner, B., and N. Herkenham (1981) An autoradiographic study of thalamo-amygdaloid connections in the rat. Anat. Rec. 199: 260A.

Turner, B. H., M. Mishkin and M. Knapp (1980) Organization of the amygdalopetal projections from modality-specific cortical association areas in the monkey. J. Comp. Neurol. 191: 515-543.

Veening, J. G. (1978) Subcortical afferents of the amygdaloid complex in the rat: An HRP study. Neurosci. Lett. 8: 197-202.

Winer, J. A., and D. K. Morest (1983) The medial division of the medial geniculate body of the cat: Implications for thalamic organization. J. Neurosci. 3: 2629-2651.

Winer, J. A., D. K. Morest, and I. T. Diamond (1988) A cytoarchitectonic atlas of the medial geniculate body of the Opossum, Didelphis virginiana, with a comment on the posterior intralaminar system of the thalamus. J. Comp. Neurol. 274: 422-448.

Whitlock, D. G., and W. J. H. Nauta (1956) Subcortical projections from the temporal neocortex in Macaca mulatta. J. Comp. Ncurol. 106: 183-212. 